\title{
Simultaneous Quantification of Seven Constituents from Zaoren Anshen Prescription and Four Endogenic Components in Rat Plasma by UHPLC-TSQ-MS/MS and the Application of the Correlation Study
}

\author{
Rong Li ${ }^{a}{ }^{a}$ Lin Wang, ${ }^{a}$ Xiao Wang, ${ }^{a}$ Dian Zhang, ${ }^{a}$ Yafeng Zhang, ${ }^{b}$ Zhuo Li, ${ }^{b}$ and Minfeng Fang $* a$ \\ ${ }^{a}$ Key Laboratory of Resource Biology and Biotechnology in Western China, Ministry of Education, Northwest \\ University; Xi'an 710069, China: and ${ }^{b}$ Xi'an Institute for Food and Drug Control; Xi'an 710054, China. \\ Received April 5, 2019; accepted May 21, 2019; advance publication released online June 5, 2019
}

\begin{abstract}
A highly rapid and sensitive ultra-performance liquid chromatography-tandem triple quadrupole mass spectrometry (UHPLC-TSQ-MS/MS) method was developed for the simultaneous determination of 7 constituents from Zaoren Anshen prescription (ZAP) and 4 endogenic components in rat plasma. The proteins in the plasma samples were removed using acetonitrile. The separation of the 11 components was performed on an Altima $\mathrm{C} 18$ column $(150 \times 4.6 \mathrm{~mm}, 5 \mu \mathrm{m})$ with acetonitrile and $0.01 \%$ formic acid water as the mobile phase. Quantification of the 11 components was performed by multiple reaction monitoring (MRM), and the electrospray ion source polarity was switched between positive and negative modes. The method exhibited good linearity for the 11 components $\left(R^{2}>\mathbf{0 . 9 9 4 2}\right)$. The lower quantitative limit for the 11 components was in the range from $0.90-9.95 \mathrm{ng} / \mathrm{mL}$. The precision was evaluated by intraday and interday assays, with all relative standard deviation (RSD)\% values within $14.92 \%$. The relative error of the accuracy ranged from -9.90 to $14.93 \%$. The recovery ranged from 73.94 to $101.06 \%$, and the matrix effects of the 7 components ranged from $\mathbf{8 0 . 0 6}$ to $\mathbf{1 0 5 . 7 0 \%}$. The developed method was successfully applied for correlation analysis for the simultaneous quantification of the 7 constituents from ZAP and 4 endogenic components in rat plasma after ZAP treatment.
\end{abstract}

Key words Zaoren Anshen prescription; pharmacokinetics; correlation; ultra-performance liquid chromatographytandem triple quadrupole mass spectrometry (UHPLC-TSQ-MS/MS)

\section{Introduction}

Insomnia, the most common sleep disorder, causes depression, anxiety and other symptoms. Approximately one third of the population suffers from this disease. ${ }^{1,2)}$ It is remarkably associated with psychiatric disorders, notably depression. ${ }^{3)}$ An imbalance of monoamine neurotransmitters leads to this depressive disorder. ${ }^{4)}$ Monoamine neurotransmitters, as the molecular targets in the diagnosis and treatment of neuropsychiatric disorders, ${ }^{5}$ ) mainly include 5-hydroxy tryptamine (5-HT), dopamine (DA), noradrenaline (NA) and 5-hydroxyindoleacetic acid (5-HIAA). Among them, 5-HT participates in the regulation of various brain functions responsible for motor activity, mood, sleep, reward and cognition. ${ }^{6)}$ Research has indicated that compared to healthy rats, the levels of NA and DA are significantly higher and 5-HT and 5-HIAA are significantly lower in insomnia rat brains. However, after oral administration of Schisandra chinensis (TurCz.) BAILL decoction, the levels of NA and DA are significantly reduced and the levels of 5-HT and 5-HIAA are significantly increased. ${ }^{7}$ Therefore, monoamine neurotransmitters are often selected as indicators for investigating drugs with anti-insomnia effects.

Researchers have searched for safe and effective antiinsomnia drugs for more than a century. Clinically available anti-insomnia drugs mainly include benzodiazepines, nonbenzodiazepines, sedative antidepressants, melatonin receptor agonists, antihistamines and natural drugs. Benzodiazepines have well-known side effects, such as sedation, muscle relaxation, amnesia, and dependence potential. ${ }^{8-10)}$ Non-benzodiazepines have the advantages of rapid absorption, no residue, low drug dependence, no rebound, and low memory damage, but fail to eliminate addiction and drug resistance. ${ }^{11)}$ Seda- tive antidepressants have many toxic side effects. ${ }^{12)}$ Melatonin receptor agonists are ideal anti-insomnia drugs with the advantages of rapid absorption, low drug dependence, low drug resistance and no rebound. ${ }^{13)}$ Antihistamines and natural drugs have auxiliary functions for treating insomnia. Thus, it is important and necessary to develop other anxiolytic drugs without adverse effects for the treatment of insomnia.

Many Traditional Chinese Medicine (TCM) prescriptions have been applied for the treatment of insomnia due to their advantages of good efficacy and few side effects. ${ }^{13)}$ Zaoren Anshen prescription (ZAP), listed in the Chinese Pharmacopoeia (2015 edition), is a classic anti-insomnia formula that is simplified from Tianwang Buxin Dan, which was first written by Ji Hong and recorded in the She Sheng Zong Yao during the Ming Dynasty. It consists of Semen Ziziphi Spinosae (Suanzaoren), Salviae Miltiorrhizae Radix et Rhizoma (Danshen) and Fructus Schisandrae Chinensis (Wuweizi). Suanzaoren, the sovereign drug in this formula, has been applied to fight insomnia and anxiety. ${ }^{14-16)}$ As the one of the main constituents, flavonoids have anxiolytic and sedative effects, ${ }^{17)}$ and its representative components, spinosin and $6{ }^{\prime \prime \prime}-$ feruloylspinosin, can promote sleep. ${ }^{18-20)}$ Danshen, the minister drug in this formula, is mainly used for promoting blood circulation, removing blood stasis, and as an adjuvant therapy for insomnia and neurasthenia. ${ }^{21,22)}$ In recent years, the water-soluble phenolic acid components of danshen have attracted increasing attention. Among them, salvianolic acid B has significant protective effects on heart and brain injuries, ${ }^{23)}$ danshensu exerts anxiolytic-like properties and hepatic-protective effects, ${ }^{24,25)}$ and protocatechualdehyde inhibits intravascular thrombosis and improves microcirculation. ${ }^{26,27)}$ Wuweizi, the assistant 
<smiles>NCC(O)c1ccc(O)c(O)c1</smiles>

NA<smiles>O=C(O)[C@H](O)Cc1ccc(O)c(O)c1</smiles>

Danshensu<smiles>NCCc1ccc(O)c(O)c1</smiles>

DA<smiles>O=Cc1ccc(O)c(O)c1</smiles>

Protocatechualdehyde

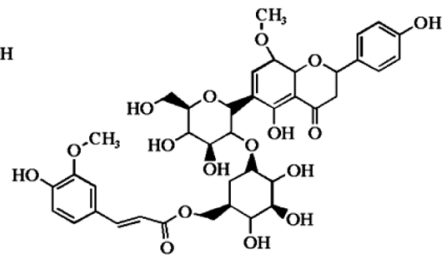

6"''-Feruloylspinosin

5-HT<smiles>O=C(O)Cc1c[nH]c2ccccc12</smiles>

5-HIAA<smiles></smiles>

Salvianolic acid B

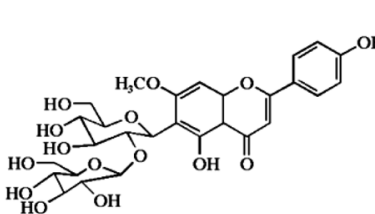

spinosin<smiles>Cc1cc(NS(=O)(=O)c2ccc(N)cc2)no1</smiles><smiles>COc1cc2c(c(OC)c1OC)-c1c(cc(OC)c(OC)c1OC)CC(C)(C)C(O)C2</smiles>

schisandrin<smiles>COc1cc2c(c(OC)c1OC)-c1c(cc(OC)c(OC)c1OC)C[C@@H](C)[C@H](C)C2</smiles>

Deoxyschisandrin

sulfamethoxazole (IS)

Fig. 1. Chemical Structures of the Analytes and IS

drug in this formula, is mainly used to dredge the liver to regulate qi and exert sedative-hypnotic activity. ${ }^{28)}$ Schisandrin and deoxyschizandrin, as its major bioactive constituents, have hepatoprotective, antioxidation and antitumor activities. ${ }^{29-31)}$

Some methods for performing pharmacokinetic studies on ZAP have been developed and applied, such as HPLCtandem triple quadrupole mass spectrometry (TSQ-MS/MS) and HPLC-diode array detector (DAD). ${ }^{32,33)}$ Additionally, in our previous study, we used an LC-electrospray ionization (ESI)-MS/MS method to simultaneously determine 7 components in ZAP and applied the method to a pharmacokinetics study in rat plasma ${ }^{34)}$ via single dose intragastric administration. However, it is still unknown whether there is correlation between the main effective components in ZAP and monoamine neurotransmitters for the treatment of insomnia. In the present study, a rapid and sensitive ultra-performance liquid chromatography-tandem triple quadrupole mass spectrometry (UHPLC-TSQ-MS/MS) method was developed for the simultaneous determination of 11 components, including 7 ZAP constituents and 4 endogenic components, in rat plasma using multi-dose continuous intragastric administration. This method was successfully applied for a correlation study on the 7 pharmaceutical ingredients and 4 monoamine neurotransmitters. The findings will be helpful to further illuminate the anti-insomnia mechanism of ZAP.

\section{Experimental}

Materials and Reagents Semen Ziziphi Spinosae, Salviae Miltiorrhizae Radix et Rhizoma and Fructus Schisandrae
Chinensis were purchased from Xi'an Tongrentang Pharmacy (Xi'an, China). They were authenticated by Professor Minfeng Fang (Northwest University, Xi'an, China), and their quality was in accordance with the Chinese Pharmacopoeia. Reference standards for NA (100169-201404), spinosin (111869-201203), deoxyschisandrin (110764-201714), danshensu (110855-201614), DA (100070-201507) and 5-HT (111656-200401) were supplied by the Shaanxi Standard and General Medical Technology Co., Ltd. (Xi'an, China). Salvianolic acid B (115939-25-8), schisandrin (2432-28-2), 6"'-feruylspinosin (77690-92-7), 5-HIAA (54-16-0) and the internal standard for sulfamethoxazole (IS 723-46-6) were obtained from Nanjing SenBeiJia Biological Technology Co., Ltd. (Nanjing, China). The chemical structures of all the components are shown in Fig. 1. All the above standards had purities greater than 98\%. Formic acid was obtained from Sigma (St. Louis, MO, U.S.A.). Water was purchased from Wahaha Group Co., Ltd. (HangZhou, China). All other chemicals and solvents were of analytical grade.

Semen Ziziphi Spinosae (fried, $1430 \mathrm{~g}$ ), Salviae Miltiorrhizae Radix et Rhizoma (286g) and Fructus Schisandrae Chinensis (fried in vinegar, $286 \mathrm{~g}$ ) were mixed at a ratio of $5: 1: 1$ and extracted twice by refluxing with $50 \%$ ethanol $(1: 8, \mathrm{w} / \mathrm{v})$, the volume of $50 \%$ ethanol added was $16 \mathrm{~L}$ at each time, and each extraction time was $2 \mathrm{~h}$. The solution obtained by filtration was concentrated to approximately $1800 \mathrm{~mL}$ by rotary evaporator, and was transferred to $2000 \mathrm{~mL}$ volumetric flask. We utilized a small amount of purified water to wash the residual drug solution on the flask wall, and transferred the solu- 
tion into the volumetric flask. We replenished purified water to the calibration line whereby $1.0 \mathrm{~g} / \mathrm{mL}$ reserve solution was obtained at constant volume. Then, the extract was diluted to $0.1 \mathrm{~g} / \mathrm{mL}$ for medicinal material content determination; the danshensu, protocatechualdehyde, spinosin, 6"'-feruylspinosin, salvianolic acid B, schisandrin and deoxyschisandrin contents were $5.22,0.52,16.77,14.25,50.17,13.02$ and $5.88 \mu \mathrm{g} / \mathrm{mL}$ respectively.

Apparatus and UHPLC-TSQ-MS/MS Conditions The UHPLC-TSQ-MS system consisted of a Thermo Scientific Ultimate 3000 LC system (Thermo Fisher Scientific Co., CA, U.S.A.) and a Thermo Scientific TSQ Quantiva MS (Thermo Fisher Scientific Co.) equipped with an electrospray ion source. Chromatographic separation was performed on an Alltima C18 column $(150 \times 4.6 \mathrm{~mm}, 5 \mu \mathrm{m}$, Alltech Co., KY, U.S.A.). The mobile phase consisted of acetonitrile (solvent A) and $0.01 \%$ formic acid water (solvent B). The flow rate was $0.3 \mathrm{~mL} / \mathrm{min}$ and the column temperature was set at $35^{\circ} \mathrm{C}$. The chromatographic gradient elution conditions were as follows: 10-35\% A for 0-8 min; 35-95\% A for $8-18 \mathrm{~min}$; $95 \%$ A for $18-25 \mathrm{~min}, 95-10 \%$ A for $25-30 \mathrm{~min}$. The volume of injected sample was $10 \mu \mathrm{L}$. The conditions for mass spectrometry were set as follows: spray voltage, $2.9 \mathrm{kV}$; ion transfer tube temperature, $350^{\circ} \mathrm{C}$; evaporator temperature, $300^{\circ} \mathrm{C}$; and quantification was achieved by switching between positive and negative ionization and using multiple reactions monitoring (MRM) mode. The MRM optimization parameters for each target analysis component and IS are shown in Table 1.

Preparation of Standards and Quality Control (QC) Samples All reference components were accurately weighted. Each standard stock solution was dissolved in methanol, and their concentrations were as follows: $0.690 \mathrm{mg} / \mathrm{mL}$ (NA), $0.995 \mathrm{mg} / \mathrm{mL}$ (DA), $0.870 \mathrm{mg} / \mathrm{mL}$ (5-HT), $0.910 \mathrm{mg} / \mathrm{mL}$ (5-HIAA), $0.220 \mathrm{mg} / \mathrm{mL}$ (danshensu), $0.180 \mathrm{mg} / \mathrm{mL}$ (protocatechualdehyde), $0.200 \mathrm{mg} / \mathrm{mL}$ (spinosin), $0.605 \mathrm{mg} / \mathrm{mL}$ (6"'-feruylspinosin), $0.240 \mathrm{mg} / \mathrm{mL}$ (salvianolic acid B), $0.320 \mathrm{mg} / \mathrm{mL}$ (schisandrin), $0.390 \mathrm{mg} / \mathrm{mL}$ (deoxyschisandrin) and $0.440 \mathrm{mg} / \mathrm{mL}$ (IS). A $1.00 \mathrm{ng} / \mathrm{mL}$ IS working standard solution was prepared by diluting the stock standard solution with methanol. The prepared solution was stored at $4^{\circ} \mathrm{C}$.

Quality control samples were prepared at three levels, including high, medium and low concentrations of NA (552, 69.0 and $13.8 \mathrm{ng} / \mathrm{mL}$, respectively), DA (796, 99.5 and $19.9 \mathrm{ng} / \mathrm{mL}$, respectively), 5-HT $(696,87.0$ and $17.4 \mathrm{ng} / \mathrm{mL}$, respectively), danshensu $(176,22$, and $4.4 \mathrm{ng} / \mathrm{mL}$, respectively), protocatechualdehyde (144, 18.0 and $3.6 \mathrm{ng} / \mathrm{mL}$, respectively), 5-HIAA (728, 91.0 and $18.2 \mathrm{ng} / \mathrm{mL}$, respectively), spinosin (160, 20.0 and $4.0 \mathrm{ng} / \mathrm{mL}$, respectively), 6"'-feruylspinosin (484, 60.5 and $12.1 \mathrm{ng} / \mathrm{mL}$, respectively), salvianolic acid B (192, 24.0 and $4.8 \mathrm{ng} / \mathrm{mL}$, respectively), schisandrin (256, 32.0 and $6.4 \mathrm{ng} / \mathrm{mL}$, respectively) and deoxyschisandrin $(312,39.0$ and $7.8 \mathrm{ng} / \mathrm{mL}$, respectively).

Animals Male Sprague-Dawley rats (SCXK 2012-2013) weighing $220 \pm 20 \mathrm{~g}$ were purchased from the Laboratory Animal Center of Xi'an Jiao Tong University (Shanxi, China). All rats were maintained in a breeding room at $22 \pm 2^{\circ} \mathrm{C}$ with $50 \pm 10 \%$ humidity and a $12 \mathrm{~h}$ light-dark cycle. The animals were fed with food and water ad libitum and adapted to the facilities for $3 \mathrm{~d}$. The animals were fasted for $12 \mathrm{~h}$ before the experiment. All animal experiments were performed in accordance with the guidelines of the Care National after the approval of the institutional ethics committee (NWU-AWC20170801R). Blank rat plasma (approximately $0.5 \mathrm{~mL}$ ) was collected via the venous plexus of the eye socket under anesthesia (anesthetized with ether). Each sample was immediately transferred to a heparinized $1.5 \mathrm{~mL}$ Eppendorf tube and centrifuged at $10000 \mathrm{rpm}$ for $10 \mathrm{~min}$ to obtain the plasma. Then, the plasma was immediately stored at $-20^{\circ} \mathrm{C}$ until analysis.

Sample Preparation The IS $(10 \mu \mathrm{L})$ and standard reference compounds $(90 \mu \mathrm{L})$ were added to the plasma samples $(100 \mu \mathrm{L})$, and then $5 \mu \mathrm{L}$ of formic acid was added to acidify the plasma samples. The mixture was extracted twice with $600 \mu \mathrm{L}$ of acetonitrile, mixed for $3 \mathrm{~min}$, and centrifuged at $10000 \mathrm{rpm}$ for $10 \mathrm{~min}$. The supernatants from each extraction were combined and evaporated to dryness under the flow of nitrogen at $4{ }^{\circ} \mathrm{C}$. The residue was dissolved in methanol $(200 \mu \mathrm{L})$ and filtered by membrane filtration. Finally, a $10-\mu \mathrm{L}$ aliquot was injected into UHPLC-TSQ-MS/MS system for analysis and detection.

The addition of formic acid was helpful to prevent peak tailing and improve the reproducibility and sensitivity of the method. To acidify the plasma samples, $5 \mu \mathrm{L}$ of formic acid was added and the mixture was gently vortexed. The mixture was extracted twice with $600 \mu \mathrm{L}$ of acetonitrile, mixed for $1 \mathrm{~min}$, and centrifuged at $9000 \mathrm{r} / \mathrm{min}$ for $10 \mathrm{~min}$. The supernatants from each extraction were combined and evaporated to dryness under the flow of nitrogen at $4^{\circ} \mathrm{C}$. The residue was subsequently dissolved in $200 \mu \mathrm{L}$ of methanol and filtered through a microporous membrane. A $10-\mu \mathrm{L}$ aliquot was used for the LC-MS/MS analysis.

Table 1. Optimized Mass Parameters for the UHPLC-TSQ-MS/MS Analysis of 11 Analytes and IS

\begin{tabular}{llcccc}
\hline \hline Components & \multicolumn{1}{c}{ Chemical formulas } & Precursor to product ion $(m / z)$ transition & Collision energy (eV) & RF lens (V) & Detected ion \\
\hline NA & $\mathrm{C}_{8} \mathrm{H}_{11} \mathrm{NO}_{3}$ & $170.11 \rightarrow 107.33$ & 19.96 & 30 & {$[\mathrm{M}+\mathrm{H}]^{+}$} \\
DA & $\mathrm{C}_{6} \mathrm{H}_{3}(\mathrm{OH})_{2}-\mathrm{CH}_{2}-\mathrm{CH}_{2}-\mathrm{NH}_{2}$ & $154.06 \rightarrow 91.33$ & 23.35 & 30 & {$[\mathrm{M}+\mathrm{H}]^{+}$} \\
5-HT & $\mathrm{C}_{10} \mathrm{H}_{12} \mathrm{~N}_{2} \mathrm{O}$ & $177.16 \rightarrow 115.33$ & 27.60 & 30 & {$[\mathrm{M}+\mathrm{H}]^{+}$} \\
5-HIAA & $\mathrm{C}_{10} \mathrm{H}_{9} \mathrm{NO}_{3}$ & $192.06 \rightarrow 118.33$ & 28.51 & 45 & {$[\mathrm{M}+\mathrm{H}]^{+}$} \\
Danshensu & $\mathrm{C}_{9} \mathrm{H}_{10} \mathrm{O}_{5}$ & $197.06 \rightarrow 135.22$ & 15.76 & 53 & {$[\mathrm{M}-\mathrm{H}]^{-}$} \\
Protocatechualdehyde & $\mathrm{C}_{7} \mathrm{H}_{6} \mathrm{O}_{3}$ & $137.06 \rightarrow 92.22$ & 23.10 & 76 & {$[\mathrm{M}-\mathrm{H}]^{-}$} \\
Spinosin & $\mathrm{C}_{28} \mathrm{H}_{32} \mathrm{O}_{15}$ & $607.14 \rightarrow 307.15$ & 38.01 & 172 & {$[\mathrm{M}-\mathrm{H}]^{-}$} \\
6"'-Feruloylspinosin & $\mathrm{C}_{38} \mathrm{H}_{40} \mathrm{O}_{18}$ & 55.00 & 180 & {$[\mathrm{M}-\mathrm{H}]^{-}$} \\
Salvianolic acid B & $\mathrm{C}_{36} \mathrm{H}_{30} \mathrm{O}_{16}$ & 28.91 & 96 & {$[\mathrm{M}-\mathrm{H}]^{-}$} \\
Schisandrin & $\mathrm{C}_{24} \mathrm{H}_{32} \mathrm{O}_{7}$ & $783.20 \rightarrow 292.17$ & 18.90 & 58 & {$[\mathrm{M}+\mathrm{H}]^{+}$} \\
Deoxyschisandrin & $\mathrm{C}_{24} \mathrm{H}_{32} \mathrm{O}_{6}$ & $717.15 \rightarrow 321.18$ & 23.90 & 89 \\
IS & $\mathrm{C}_{10} \mathrm{H}_{11} \mathrm{~N}_{3} \mathrm{O}_{3} \mathrm{~S}$ & $433.20 \rightarrow 384.37$ & 24.87 & {$[\mathrm{M}+\mathrm{H}]^{+}$} \\
\hline
\end{tabular}




\section{Method Validation}

Specificity

The specificity of the established method was evaluated by comparing the MRM chromatograms of the blank plasma, the blank plasma mixed with standards and the plasma after oral administration. The peak shapes for the standards and plasma samples were symmetrical, and there was no other interference from endogenous impurities. The separation degree of each component was good, and each component could be detected and reproduced.

As the 4 monoamines were present in rat blank plasma, the established method only needed to ensure that their chromatographic peak retention times and areas were relatively stable in blank plasma.

Calibration Curve and Lower Limit of Quantification (LLOQ) The calibration curves for all the plasma samples were determined by plotting the peak area ratios of the target components from the IS against the concentrations of the standards with weight coefficient of $1 / x^{2}$. The blank plasma after protein precipitation was used to dilute the standard solutions into a series of mixed standard solutions, and the internal standard solution was added in proportion for determination. The quantification of the 4 monoamine neurotransmitters method required subtracting the values for blank plasma. The LLOQ was defined as the lowest concentration in the calibration curve, a signal-to-noise ratio greater than 10 and could be confirmed by an acceptable accuracy (RE within 80-120\%) and a precision less than $20 \%$.

Accuracy and Precision The intra and interday precision and accuracy were evaluated by testing the quality control samples. For the intraday testing, we evaluated the high, middle and low concentration quality control samples $(n=6)$ six times each. For the interday testing, each quality control sample concentration level was tested on three consecutive days. The precision results were expressed as the relative standard deviation (RSD) and the accuracy results were expressed as the relative error (RE). Acceptable RSD values cannot exceed $15 \%$ and the RE value cannot exceed $20 \%$.

Extraction Recovery and Matrix Effect The extraction recovery was determined by comparison with the quality con-

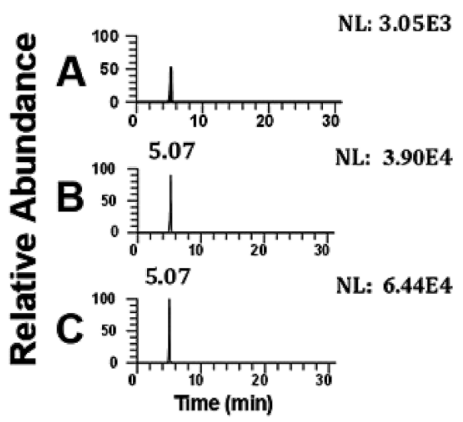

NA

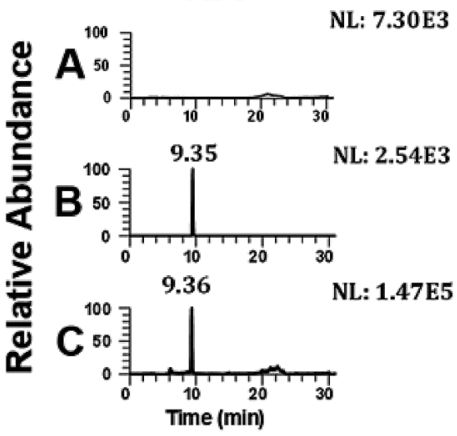

Danshensu
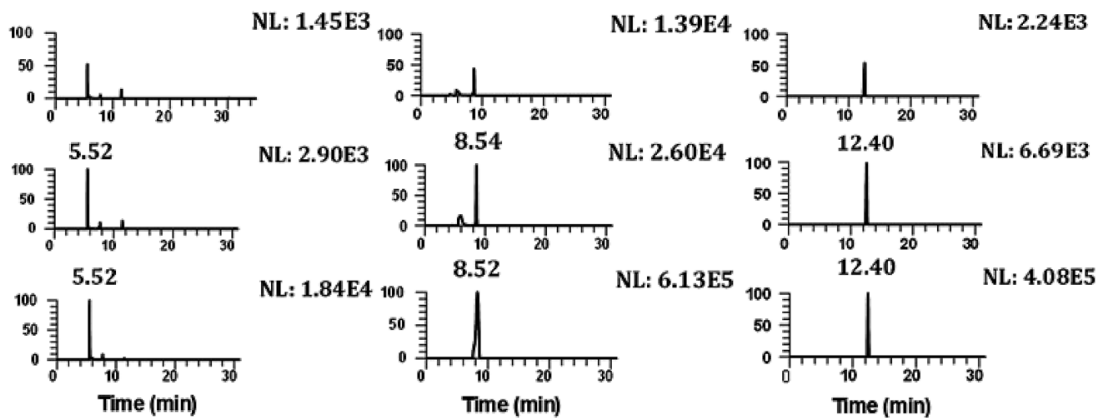

DA

5-HT

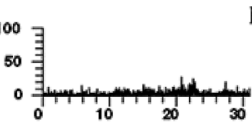

NL: 2.81E2
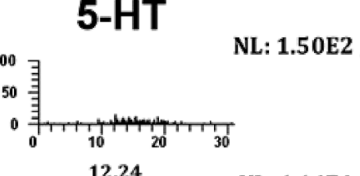

5-HIAA

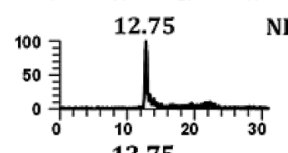

NL: $4.32 \mathrm{E}$

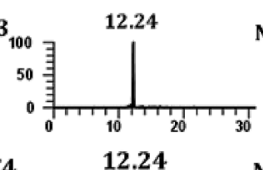

$\begin{array}{lll}\text { NL: } 1.14 E 4 & 13.59 & \text { NL: } 2.29 E 4\end{array}$

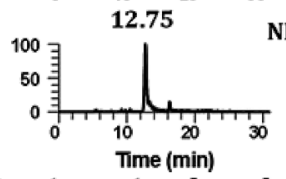

NL: 2.67E4

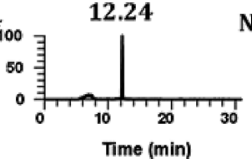

Protocatechualdehyde Spinosin
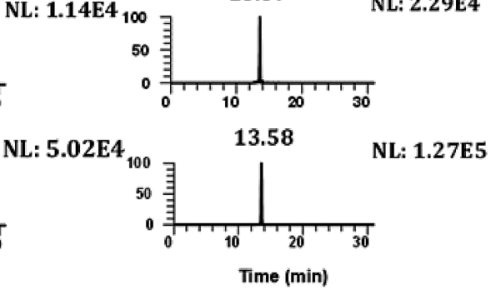

6"'-Feruloylspinosin
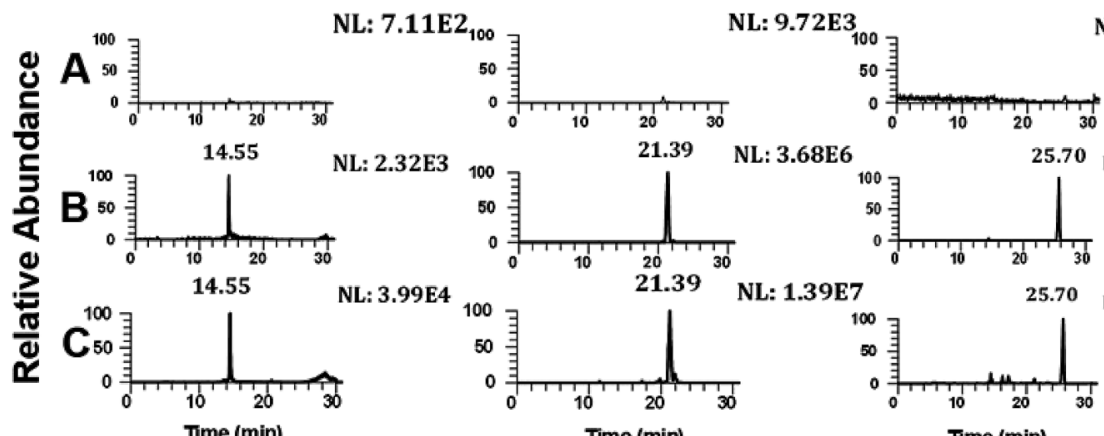

NL: 1.00E2

NL: $3.00 E 2$

\section{Salvianolic acid B Schisandrin}

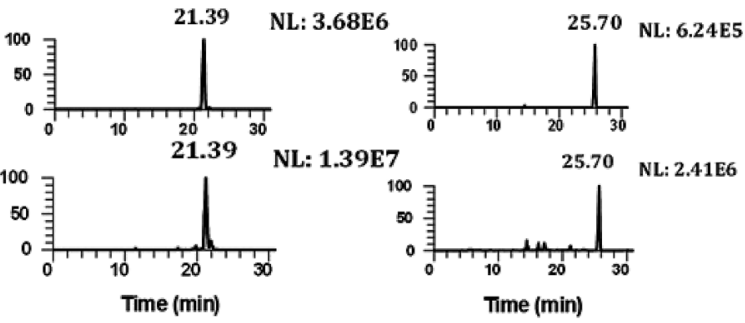

Deoxyschisandrin
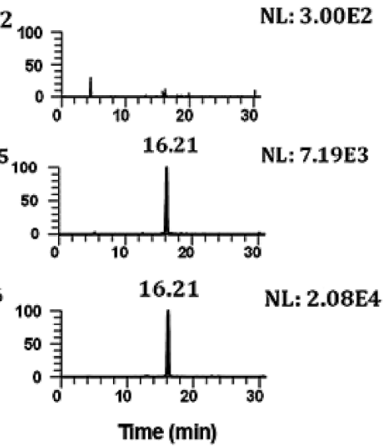

IS

Fig. 2. MRM Chromatograms of Each Components in Rat Plasma: (A) Blank Plasma; (B) Blank Plasma Spiked with the Eleven Analytes at LLOQ and IS; (C) Plasma Sample Collected at $0.25 \mathrm{~h}$ after Oral of ZAP Extract 
trol samples at three concentration levels, including the high, medium and low concentrations. We detected and compared the mean peak values from the extracted plasma samples and the postextracted supernatants spiked with working solutions at the same concentration. The plasma samples were tested with each quality control level six times. Meanwhile, one IS concentration level was prepared to detect the IS recovery rate. The matrix effect of plasmas was determined by con- trasting the peak areas of the target components dissolved in the blank plasma samples with those dissolved in methanol.

Stability The stability was detected using the quality control samples at three concentration levels under different storage conditions as follows: short-term stability, at room temperature for six hours; long-term stability, at $-80^{\circ} \mathrm{C}$ frozen for $30 \mathrm{~d}$; at $4^{\circ} \mathrm{C}$ in a sampler and three freeze-thaw cycles stability, from $-20^{\circ} \mathrm{C}$ to room temperature. When the $\mathrm{RE} \%$

Table 2. Calibration Curve, Linear Range and LLOQ for 11 Components in Rat Plasma $(n=6)$

\begin{tabular}{|c|c|c|c|c|}
\hline Compounds & Calibration curve & Correlation coefficient $\left(R^{2}\right)$ & Linear range $(\mathrm{ng} / \mathrm{mL})$ & LLOQ (ng/mL) \\
\hline 5-HT & $y=3.3100 x-10.476$ & 0.9993 & $8.70-870$ & 8.70 \\
\hline NA & $y=0.7772 x+2.8915$ & 0.9945 & $6.90-690$ & 6.90 \\
\hline DA & $y=1.4121 x+45.939$ & 0.9942 & $9.95-995$ & 9.95 \\
\hline 5-HIAA & $y=2.7542 x+13.327$ & 0.9969 & $9.10-910$ & 9.10 \\
\hline Danshensu & $y=0.3506 x+0.6158$ & 0.9996 & $2.20-220$ & 2.20 \\
\hline Protocatechualdehyde & $y=4.0852 x+2.3658$ & 0.9979 & $0.90-180$ & 0.90 \\
\hline Spinosin & $y=1.5075 x+0.0458$ & 0.9942 & $1.00-200$ & 1.00 \\
\hline Salvianolic acid B & $y=3.1595 x+9.3306$ & 0.9980 & $2.40-240$ & 2.40 \\
\hline Schisandrin & $y=0.6585 x+2.7461$ & 0.9993 & $3.20-320$ & 3.20 \\
\hline $6^{\prime \prime \prime}-$ Feruloylspinosin & $y=1.9681 x+20.099$ & 0.9988 & $6.05-650$ & 6.05 \\
\hline Deoxyschisandrin & $y=1.2531 x+1.9475$ & 0.9960 & $3.90-390$ & 3.90 \\
\hline
\end{tabular}

Table 3. Precision, Accuracy, Recovery and Matrix Effect of the 11 Components in Rat Plasma Samples

\begin{tabular}{|c|c|c|c|c|c|c|c|c|c|}
\hline \multirow[b]{2}{*}{ Compounds } & \multirow{2}{*}{$\begin{array}{c}\text { Spiked } \\
\text { concentration } \\
(\mathrm{ng} / \mathrm{mL})\end{array}$} & \multicolumn{3}{|c|}{ Intra-day $(n=6)$} & \multicolumn{3}{|c|}{ Inter-day $(n=6 \times 3)$} & \multirow{2}{*}{$\begin{array}{c}\text { Extraction } \\
\text { recovery } \\
(\%)\end{array}$} & \multirow{2}{*}{$\begin{array}{c}\text { Matrix effec } \\
(\%)\end{array}$} \\
\hline & & Mean (ng/mL) & $\begin{array}{l}\text { RSD } \\
(\%)\end{array}$ & $\begin{array}{c}\text { Accuracy } \\
(\%)\end{array}$ & Mean (ng/mL) & $\begin{array}{c}\text { RSD } \\
(\%)\end{array}$ & $\begin{array}{c}\text { Accuracy } \\
(\%)\end{array}$ & & \\
\hline \multirow[t]{3}{*}{$5-\mathrm{HT}$} & 696 & $646.41 \pm 10.60$ & 1.60 & -7.10 & $670.56 \pm 13.32$ & 1.64 & -7.13 & $80.29 \pm 0.14$ & $90.59 \pm 0.15$ \\
\hline & 87 & $78.39 \pm 2.40$ & 3.10 & -9.90 & $79.88 \pm 1.76$ & 3.06 & -9.90 & $81.52 \pm 0.11$ & $101.30 \pm 0.13$ \\
\hline & 17.4 & $17.35 \pm 0.11$ & 3.50 & 3.00 & $17.36 \pm 0.36$ & 0.62 & -0.31 & $96.57 \pm 0.07$ & $80.06 \pm 0.06$ \\
\hline \multirow[t]{3}{*}{ NA } & 552 & $543.36 \pm 6.20$ & 1.10 & -1.60 & $553.00 \pm 11.90$ & 1.14 & -1.57 & $87.71 \pm 0.29$ & $87.30 \pm 0.28$ \\
\hline & 69 & $72.17 \pm 2.06$ & 2.90 & 4.60 & $76.11 \pm 1.13$ & 2.86 & 4.60 & $86.84 \pm 0.05$ & $101.00 \pm 0.06$ \\
\hline & 13.8 & $14.55 \pm 2.17$ & 14.90 & 5.40 & $14.52 \pm 0.41$ & 14.92 & 5.44 & $98.07 \pm 0.06$ & $100.42 \pm 0.07$ \\
\hline \multirow[t]{3}{*}{ DA } & 796 & $788.96 \pm 8.17$ & 1.00 & -0.90 & $753.40 \pm 9.97$ & 1.03 & -0.88 & $82.79 \pm 0.14$ & $102.94 \pm 0.17$ \\
\hline & 99.5 & $98.54 \pm 2.06$ & 2.10 & -1.00 & $106.03 \pm 3.13$ & 2.09 & -0.96 & $76.59 \pm 0.09$ & $84.55 \pm 0.10$ \\
\hline & 19.9 & $22.11 \pm 0.08$ & 0.30 & 11.10 & $21.5 \pm 0.48$ & 0.34 & 11.13 & $97.80 \pm 0.02$ & $94.62 \pm 0.02$ \\
\hline \multirow[t]{3}{*}{ 5-HIAA } & 728 & $775.49 \pm 12.21$ & 1.60 & -6.50 & $744.51 \pm 8.53$ & 1.64 & 6.52 & $96.59 \pm 0.07$ & $102.61 \pm 0.07$ \\
\hline & 91 & $89.82 \pm 2.66$ & 3.00 & -1.30 & $87.76 \pm 2.36$ & 3.06 & -1.30 & $84.25 \pm 0.10$ & $88.26 \pm 0.10$ \\
\hline & 18.2 & $17.80 \pm 0.23$ & 1.30 & -2.20 & $19.21 \pm 1.61$ & 1.31 & -2.17 & $98.26 \pm 0.05$ & $92.98 \pm 0.05$ \\
\hline \multirow[t]{3}{*}{ Danshensu } & 176 & $166.55 \pm 2.33$ & 1.40 & -5.30 & $188.67 \pm 5.70$ & 1.40 & -5.37 & $82.39 \pm 0.03$ & $103.40 \pm 0.04$ \\
\hline & 22 & $22.76 \pm 2.86$ & 12.60 & 3.50 & $22.15 \pm 0.60$ & 12.57 & 3.47 & $89.23 \pm 0.05$ & $99.05 \pm 0.06$ \\
\hline & 4.4 & $4.26 \pm 0.06$ & 1.50 & -3.20 & $3.93 \pm 0.44$ & 1.51 & -3.21 & $98.93 \pm 0.17$ & $90.19 \pm 0.16$ \\
\hline \multirow[t]{3}{*}{ Protocatechualdehyde } & 144 & $136.46 \pm 1.94$ & 1.40 & -5.20 & $133.60 \pm 2.08$ & 1.42 & -5.24 & $93.90 \pm 0.12$ & $85.40 \pm 0.11$ \\
\hline & 18 & $17.18 \pm 0.38$ & 2.20 & -4.60 & $15.72 \pm 0.33$ & 2.20 & -4.57 & $83.63 \pm 0.10$ & $87.20 \pm 0.10$ \\
\hline & 3.6 & $3.88 \pm 0.44$ & 11.30 & 7.80 & $3.79 \pm 0.10$ & 11.3 & 7.76 & $99.63 \pm 0.03$ & $84.26 \pm 0.03$ \\
\hline \multirow[t]{3}{*}{ Spinosin } & 160 & $145.41 \pm 6.40$ & 4.40 & -9.10 & $150.79 \pm 7.37$ & 4.40 & -9.12 & $87.86 \pm 0.13$ & $89.15 \pm 0.14$ \\
\hline & 20 & $20.84 \pm 0.49$ & 2.30 & 4.20 & $18.15 \pm 0.40$ & 2.34 & 4.22 & $85.89 \pm 0.08$ & $96.52 \pm 0.09$ \\
\hline & 4 & $4.37 \pm 0.11$ & 2.40 & 9.30 & $4.42 \pm 0.07$ & 2.41 & 9.29 & $98.64 \pm 0.04$ & $87.77 \pm 0.03$ \\
\hline \multirow[t]{3}{*}{ Salvianolic acid B } & 192 & $178.72 \pm 2.53$ & 1.40 & -7.00 & $177.08 \pm 4.05$ & 1.42 & -6.92 & $98.16 \pm 0.01$ & $100.85 \pm 0.01$ \\
\hline & 24 & $26.28 \pm 1.25$ & 4.70 & 9.50 & $22.33 \pm 0.75$ & 4.75 & 9.49 & $93.27 \pm 0.07$ & $101.53 \pm 0.08$ \\
\hline & 4.8 & $5.28 \pm 0.33$ & 6.30 & 10.00 & $4.90 \pm 0.38$ & 6.31 & 10.00 & $99.59 \pm 0.10$ & $93.64 \pm 0.10$ \\
\hline \multirow[t]{3}{*}{ Schisandrin } & 256 & $232.09 \pm 8.13$ & 3.50 & -9.30 & $260.39 \pm 9.91$ & 3.50 & -9.34 & $93.28 \pm 0.06$ & $98.07 \pm 0.06$ \\
\hline & 32 & $32.39 \pm 3.41$ & 10.50 & 1.20 & $29.67 \pm 0.99$ & 10.53 & 1.21 & $85.71 \pm 0.05$ & $101.77 \pm 0.06$ \\
\hline & 6.4 & $5.88 \pm 0.06$ & 10.20 & 3.00 & $6.37 \pm 0.53$ & 1.01 & -8.17 & $101.06 \pm 0.22$ & $96.25 \pm 0.21$ \\
\hline \multirow[t]{3}{*}{$6^{\prime \prime \prime}-$ Feruloylspinosin } & 484 & $489.41 \pm 14.71$ & 3.00 & 1.10 & $426.21 \pm 5.09$ & 3.00 & 1.12 & $90.75 \pm 0.11$ & $95.16 \pm 11.0$ \\
\hline & 60.5 & $65.60 \pm 3.09$ & 4.70 & 8.40 & $66.8 \pm 1.87$ & 4.72 & 8.42 & $86.22 \pm 0.12$ & $97.55 \pm 0.14$ \\
\hline & 12.1 & $13.91 \pm 0.33$ & 2.40 & 14.90 & $13.67 \pm 0.59$ & 2.36 & 14.93 & $94.33 \pm 0.06$ & $98.93 \pm 0.06$ \\
\hline \multirow[t]{3}{*}{ Deoxyschisandrin } & 312 & $296.78 \pm 4.67$ & 1.60 & -4.90 & $312.28 \pm 5.77$ & 1.57 & -4.88 & $83.83 \pm 0.14$ & $98.30 \pm 0.17$ \\
\hline & 39 & $35.74 \pm 1.05$ & 2.90 & -8.40 & $35.52 \pm 0.32$ & 2.94 & -8.36 & $73.94 \pm 0.13$ & $82.29 \pm 0.15$ \\
\hline & 7.8 & $7.45 \pm 0.06$ & 6.90 & 2.40 & $7.93 \pm 0.27$ & 0.87 & -4.47 & $98.04 \pm 0.06$ & $105.70 \pm 0.07$ \\
\hline
\end{tabular}


was within $\pm 15 \%$ under four different conditions, the methods were thought to be stable.

Pharmacokinetic Study Male Sprague-Dawley rats were fasted overnight and allowed access to water before the experiment. After obtaining the blank plasma samples, each rat was given the same dose of ZAP $(15 \mathrm{~g} / \mathrm{kg})$ for 7 consecutive days, once a day in the morning. Then, $0.20 \mathrm{~mL}$ of blood samples were quickly collected at different time points $(0.083,0.25,0.5$, $1,2,3,5,7,9,12$ and 24h) after administration. The collected blood samples were centrifuged at $9000 \mathrm{rpm}$ and $4^{\circ} \mathrm{C}$ for $10 \mathrm{~min}$, and the supernatant was extracted twice with acetonitrile. Finally, the supernatant was evaporated to dryness under nitrogen at $40^{\circ} \mathrm{C}$. All of the samples were stored at $-20^{\circ} \mathrm{C}$.

Statistical Analysis The pharmacokinetics parameters, including the maximum plasma concentration $\left(C_{\max }\right)$, area under the concentration-time curve $(A U C)$, mean retention time $(M R T)$, half-life $\left(T_{1 / 2}\right)$, time to reach the maximum concentration $\left(T_{\max }\right)$ and clearance rate $\left(C L_{\mathrm{z}} / F\right)$, were calculated with the DAS 3.0 software (Bio Guider Co., Shanghai, China) using noncompartmental analysis of the plasma concentration $v s$. time date. The content level correlation for the 11 components was analyzed by the Pearson coefficient method in the IBM SPSS 20.0 software (SPSS, Chicago, U.S.A.). $p$ Values less than 0.05 were considered statistically significant. The comparison of multiple groups was analyzed by Duncan analysis under one-way ANOVA.

\section{Results and Discussion}

Optimization of the UHPLC-TSQ-MS/MS Conditions

The complexity and diversity of the chemical components in TCM compounds make it challenging to quantify exogenous and endogenous components simultaneously in rat plasma after orally administration of ZAP. In this study, three different types of columns were used, including a Thermo Scientific $\mathrm{C} 18(100 \times 2.1 \mathrm{~mm}, 1.9 \mu \mathrm{m})$, Agilent HC-C18 $(250 \times 4.6 \mathrm{~mm}$, $5 \mu \mathrm{m})$ and Alltima C18 Column $(150 \times 4.6 \mathrm{~mm}, 5 \mu \mathrm{m})$, among which Alltima C18 Column $(150 \times 4.6 \mathrm{~mm}, 5 \mu \mathrm{m})$ obtained good separation effects. Moreover, to optimize the chromatographic behavior of each component, different mobile phases were examined, including acetonitrile-water, methanol-water, and acetonitrile- $-0.01 \%$ formic acid. We found that the acetonitrile- $-0.01 \%$ formic acid system could separate the analytical components in gradient elution mode. Moreover, the addition of $0.1 \%$ formic acid could increase the responses and promote

Table 4. Stability of 11 Components in Rat Plasma Samples $(n=6)$

\begin{tabular}{|c|c|c|c|c|c|c|c|c|c|}
\hline \multirow[b]{2}{*}{ Components } & \multirow{2}{*}{$\begin{array}{c}\text { Spiked } \\
\text { concentration } \\
(\mathrm{ng} / \mathrm{mL})\end{array}$} & \multicolumn{2}{|c|}{ Room temperature for $24 \mathrm{~h}$} & \multicolumn{2}{|c|}{ Samples at $4^{\circ} \mathrm{C}$ for $24 \mathrm{~h}$} & \multicolumn{2}{|c|}{ Samples at $-80^{\circ} \mathrm{C}$ for 4 weeks } & \multicolumn{2}{|c|}{ Three freeze-thaw cycle } \\
\hline & & $\begin{array}{c}\text { Measured } \\
\text { concentration } \\
(\mathrm{ng} / \mathrm{mL})\end{array}$ & $\begin{array}{c}\text { Accuracy } \\
\text { RE } \\
(\%)\end{array}$ & $\begin{array}{c}\text { Measured } \\
\text { concentration } \\
(\mathrm{ng} / \mathrm{mL})\end{array}$ & $\begin{array}{c}\text { Accuracy } \\
\text { RE } \\
(\%)\end{array}$ & $\begin{array}{c}\text { Measured } \\
\text { concentration } \\
(\mathrm{ng} / \mathrm{mL})\end{array}$ & $\begin{array}{c}\text { Accuracy } \\
\text { RE } \\
(\%)\end{array}$ & $\begin{array}{c}\text { Measured } \\
\text { concentration } \\
(\mathrm{ng} / \mathrm{mL})\end{array}$ & $\begin{array}{c}\text { Accuracy } \\
\text { RE } \\
(\%)\end{array}$ \\
\hline \multirow[t]{3}{*}{$5-\mathrm{HT}$} & 696 & $688.46 \pm 13.36$ & 0.88 & $658.55 \pm 10.41$ & -5.40 & $719.44 \pm 18.00$ & 3.37 & $704.50 \pm 26.78$ & 1.22 \\
\hline & 87 & $77.29 \pm 2.72$ & -2.33 & $76.35 \pm 4.31$ & -12.24 & $77.41 \pm 2.20$ & -11.02 & $86.16 \pm 3.94$ & -0.97 \\
\hline & 17.4 & $16.07 \pm 0.23$ & 8.22 & $15.75 \pm 0.54$ & -9.49 & $18.49 \pm 0.50$ & 6.29 & $16.59 \pm 0.64$ & -4.64 \\
\hline \multirow[t]{3}{*}{ NA } & 552 & $564.00 \pm 10.63$ & 2.17 & $559.30 \pm 12.63$ & 1.32 & $566.63 \pm 18.68$ & 2.65 & $553.11 \pm 24.44$ & 0.20 \\
\hline & 69 & $75.11 \pm 2.82$ & -4.92 & $74.57 \pm 2.95$ & 8.07 & $75.94 \pm 4.04$ & 10.06 & $75.11 \pm 3.37$ & 8.85 \\
\hline & 13.8 & $15.11 \pm 0.63$ & -1.08 & $14.35 \pm 1.28$ & 4.00 & $14.24 \pm 1.94$ & 3.19 & $13.65 \pm 0.96$ & -1.05 \\
\hline \multirow[t]{3}{*}{ DA } & 796 & $756.83 \pm 11.15$ & 9.90 & $742.33 \pm 14.94$ & -6.74 & $784.33 \pm 21.43$ & -1.47 & $782.20 \pm 35.73$ & -1.73 \\
\hline & 99.5 & $103.40 \pm 3.55$ & -1.79 & $102.81 \pm 2.48$ & 3.33 & $105.24 \pm 3.39$ & 5.77 & $109.61 \pm 2.71$ & 10.17 \\
\hline & 19.9 & $22.82 \pm 0.22$ & 4.97 & $22.44 \pm 0.30$ & 12.76 & $22.32 \pm 0.14$ & 12.17 & $21.69 \pm 0.21$ & 8.97 \\
\hline \multirow[t]{3}{*}{ 5-HIAA } & 728 & $764.21 \pm 12.30$ & -11.61 & $739.46 \pm 15.56$ & 1.57 & $734.87 \pm 21.26$ & 0.94 & $774.61 \pm 29.35$ & 6.40 \\
\hline & 91 & $93.88 \pm 3.51$ & 3.16 & $91.70 \pm 4.56$ & 0.77 & $93.79 \pm 4.46$ & 3.06 & $96.40 \pm 2.41$ & 5.94 \\
\hline & 18.2 & $16.94 \pm 1.22$ & -9.71 & $16.77 \pm 0.58$ & -7.87 & $16.29 \pm 1.03$ & -10.51 & $17.15 \pm 1.25$ & -5.77 \\
\hline \multirow[t]{3}{*}{ Danshensu } & 176 & $193.43 \pm 3.58$ & 10.08 & $187.53 \pm 4.12$ & 6.55 & $175.11 \pm 4.71$ & -0.50 & $184.30 \pm 6.83$ & 4.72 \\
\hline & 22 & $20.69 \pm 0.88$ & 3.49 & $20.13 \pm 0.68$ & -8.52 & $19.76 \pm 0.86$ & -10.18 & $22.62 \pm 0.91$ & 2.82 \\
\hline & 4.4 & $3.96 \pm 0.22$ & 8.85 & $3.93 \pm 0.42$ & -10.64 & $4.96 \pm 0.29$ & 12.70 & $4.31 \pm 0.33$ & -2.07 \\
\hline \multirow[t]{3}{*}{ Protocatechualdehyde } & 144 & $141.42 \pm 2.70$ & 3.92 & $139.38 \pm 2.99$ & -3.21 & $131.32 \pm 4.31$ & -8.81 & $139.42 \pm 5.24$ & -3.18 \\
\hline & 18 & $15.91 \pm 0.64$ & -11.16 & $15.54 \pm 0.65$ & -13.68 & $15.58 \pm 0.65$ & -13.44 & $17.41 \pm 0.56$ & -3.26 \\
\hline & 3.6 & $3.95 \pm 0.22$ & -5.95 & $3.73 \pm 0.09$ & 3.65 & $3.54 \pm 0.18$ & -1.57 & $3.57 \pm 0.14$ & -0.92 \\
\hline \multirow[t]{3}{*}{ Spinosin } & 160 & $161.40 \pm 2.07$ & 19.60 & $147.44 \pm 1.83$ & -7.85 & $176.60 \pm 6.19$ & 10.38 & $144.42 \pm 6.34$ & -9.74 \\
\hline & 20 & $18.06 \pm 0.75$ & -2.26 & $17.54 \pm 1.17$ & -12.28 & $17.99 \pm 0.54$ & -10.05 & $19.94 \pm 0.68$ & -0.30 \\
\hline & 4 & $4.34 \pm 0.16$ & -3.39 & $4.32 \pm 0.11$ & 7.91 & $4.58 \pm 0.19$ & 14.58 & $4.55 \pm 0.23$ & 13.71 \\
\hline \multirow[t]{3}{*}{ Salvianolic acid B } & 192 & $207.78 \pm 4.29$ & -7.67 & $199.14 \pm 2.80$ & 3.72 & $183.73 \pm 5.27$ & -4.31 & $176.97 \pm 7.07$ & -7.83 \\
\hline & 24 & $23.46 \pm 1.12$ & -9.99 & $22.52 \pm 1.16$ & -6.17 & $22.33 \pm 1.01$ & -6.94 & $24.62 \pm 1.14$ & 2.60 \\
\hline & 4.8 & $4.98 \pm 0.42$ & 9.80 & $4.91 \pm 0.33$ & 2.31 & $5.03 \pm 0.40$ & 4.83 & $4.91 \pm 0.57$ & 2.28 \\
\hline \multirow[t]{3}{*}{ Schisandrin } & 256 & $281.81 \pm 4.94$ & -6.92 & $257.40 \pm 13.27$ & 0.55 & $257.42 \pm 12.80$ & 0.56 & $252.04 \pm 12.53$ & -1.55 \\
\hline & 32 & $30.92 \pm 1.53$ & -8.59 & $28.80 \pm 1.94$ & -9.99 & $29.01 \pm 1.45$ & -9.36 & $31.98 \pm 2.08$ & -0.05 \\
\hline & 6.4 & $5.69 \pm 0.56$ & 8.99 & $5.77 \pm 0.31$ & -9.84 & $5.69 \pm 0.47$ & -11.03 & $6.72 \pm 0.73$ & 4.94 \\
\hline \multirow[t]{3}{*}{$6^{\prime \prime \prime}$-Feruloylspinosin } & 484 & $472.73 \pm 13.13$ & -9.04 & $475.43 \pm 13.29$ & -1.77 & $468.94 \pm 11.72$ & -3.11 & $460.46 \pm 20.41$ & -4.86 \\
\hline & 60.5 & $72.36 \pm 2.30$ & 9.47 & $69.34 \pm 2.03$ & 14.62 & $60.28 \pm 4.35$ & -0.36 & $61.46 \pm 3.95$ & 1.59 \\
\hline & 12.1 & $13.19 \pm 1.17$ & 14.68 & $13.37 \pm 0.87$ & 10.49 & $12.83 \pm 1.37$ & 6.00 & $13.42 \pm 1.48$ & 10.92 \\
\hline \multirow[t]{3}{*}{ Deoxyschisandrin } & 312 & $322.90 \pm 6.76$ & 3.74 & $312.36 \pm 5.85$ & 0.12 & $318.81 \pm 7.46$ & 2.18 & $327.62 \pm 14.27$ & 5.01 \\
\hline & 39 & $35.48 \pm 1.45$ & -11.09 & $35.17 \pm 2.08$ & -9.81 & $42.91 \pm 1.37$ & 10.03 & $40.17 \pm 1.77$ & 3.01 \\
\hline & 7.8 & $8.13 \pm 0.48$ & 4.23 & $8.30 \pm 0.38$ & 6.36 & $8.18 \pm 0.54$ & 4.88 & $8.70 \pm 0.55$ & 11.48 \\
\hline
\end{tabular}


good separation and better peak shapes for the analytes.

To identify the optimal ESI conditions for the detection of each component, both positive and negative ion modes were evaluated. Among the 11 components and IS, the sensitivity for NA, DA, 5-HT, 5-HIAA, schisandrin and deoxyschisandrin was higher using positive ion mode detection, whereas that for danshensu, protocatechualdehyde, spinosin, 6"'-feruylspinosin, salvianolic acid B and IS was higher using negative ion mode detection. In previous studies, schisandrin was measured by LC-MS/MS in both negative ${ }^{35)}$ and positive ${ }^{36)}$ ion modes. In this study, by comparing the response of schisandrin in negative and positive ion modes, we found that the response of schisandrin in positive ion mode was much higher than in negative mode. Therefore, we used MRM scanning for quantification, and the ESI source polarity was switched between positive and negative ion modes in a single run.

Previous researchers have used RP-HPLC-UV, HPLC$\mathrm{MS} / \mathrm{MS}$, and HPLC-DAD methods to quantify single active components and multiple active components from ZAP in plasma and tissues, respectively. ${ }^{32,33,37,38)}$ Compared with pre-
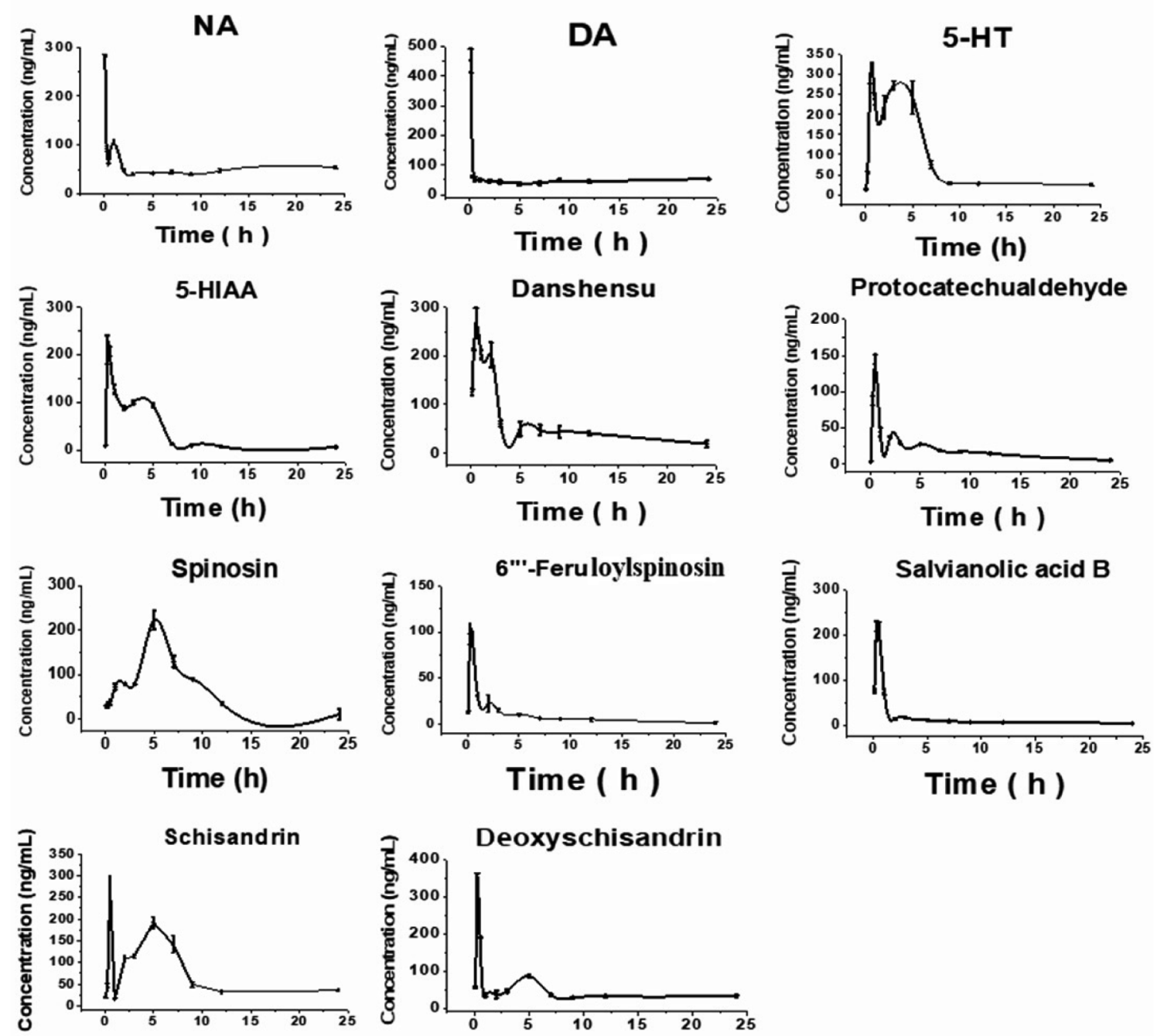

Time ( h )

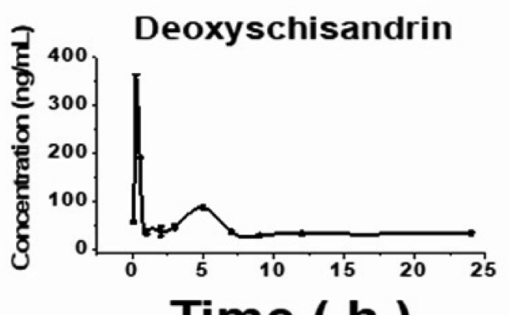

Fig. 3. Mean Plasma Concentration-Time Curves of 11 Components after Oral ZAP in Rats

Mean \pm S.D., $n=6$.

Table 5. Pharmacokinetic Parameters of 7 Components from ZAP in Rats after Given the ZAP

\begin{tabular}{|c|c|c|c|c|c|c|c|}
\hline Compounds & $T_{1 / 2}(\mathrm{~h})$ & $T_{\max }(\mathrm{h})$ & $C_{\max }(\mathrm{ng} / \mathrm{mL})$ & $A U C_{0-t}(\mathrm{ngh} / \mathrm{mL})$ & $A U C_{0-\infty}(\mathrm{ngh} / \mathrm{mL})$ & $M R T_{0 \rightarrow t}(\mathrm{~h})$ & $C L_{\mathrm{z}} / F(\mathrm{~L} / \mathrm{h} / \mathrm{kg})$ \\
\hline Danshensu & $2.85 \pm 0.89$ & $0.46 \pm 0.10$ & $267.83 \pm 32.32$ & $1000.00 \pm 0.33$ & $1104.11 \pm 108.53$ & $3.41 \pm 0.10$ & $5.75 \pm 0.62$ \\
\hline Protocatechualdehyde & $3.45 \pm 0.30$ & $0.50 \pm 0.00$ & $137.78 \pm 14.73$ & $225.01 \pm 10.90$ & $255.39 \pm 23.95$ & $7.53 \pm 0.55$ & $45.28 \pm 3.05$ \\
\hline Spinosin & $4.64 \pm 1.59$ & $5.46 \pm 0.10$ & $328.92 \pm 64.21$ & $1754.56 \pm 97.72$ & $2262.12 \pm 144.46$ & $7.91 \pm 0.78$ & $6.95 \pm 1.06$ \\
\hline Salvianolic acid B & $2.74 \pm 3.08$ & $0.42 \pm 0.13$ & $224.80 \pm 4.90$ & $455.66 \pm 6.75$ & $559.05 \pm 18.15$ & $4.36 \pm 0.20$ & $26.85 \pm 0.83$ \\
\hline Schisandrin & $4.72 \pm 0.32$ & $0.50 \pm 0.00$ & $268.16 \pm 34.02$ & $1660.70 \pm 28.23$ & $1633.39 \pm 78.52$ & $8.38 \pm 0.33$ & $7.69 \pm 3.22$ \\
\hline $6^{\prime \prime \prime}$-Feruloylspinosin & $2.26 \pm 0.00$ & $0.25 \pm 0.00$ & $77.68 \pm 12.20$ & $303.24 \pm 11.83$ & $304.25 \pm 10.49$ & $10.48 \pm 0.53$ & $43.45 \pm 14.55$ \\
\hline Deoxyschisandrin & $7.73 \pm 0.38$ & $0.25 \pm 0.00$ & $351.74 \pm 12.45$ & $945.09 \pm 25.91$ & $1143.07 \pm 122.52$ & $9.67 \pm 0.44$ & $7.12 \pm 6.61$ \\
\hline
\end{tabular}


Table 6. Correlation Analysis of Concentration for 11 Components in Rats after Given the ZAP

\begin{tabular}{|c|c|c|c|c|c|c|c|c|c|c|c|}
\hline Components & NA & DA & $5-\mathrm{HT}$ & 5-HIAA & Protocatechualdehyde & Danshensu & Spinosin & 6"'-Feruylspinosin & $\begin{array}{l}\text { Salvianolic } \\
\text { acid B }\end{array}$ & Schisandrin & Deoxyschisandrin \\
\hline NA & 1 & - & - & - & - & - & - & - & - & - & - \\
\hline DA & $0.783 * *$ & 1 & - & - & - & - & - & - & - & - & - \\
\hline 5-HT & -0.130 & 0.301 & 1 & - & - & - & - & - & - & - & - \\
\hline 5 -HIAA & -0.512 & -0.547 & 0.341 & 1 & - & - & - & - & - & - & - \\
\hline Protocatechualdehyde & 0.020 & 0.242 & 0.525 & -0.237 & 1 & - & - & - & - & - & - \\
\hline Danshensu & 0.285 & 0.102 & $0.852^{* *}$ & $-0.617 *$ & 0.450 & 1 & - & - & - & - & - \\
\hline Spinosin & -0.048 & 0.384 & $0.876^{* *}$ & 0.441 & 0.542 & $0.901^{* *}$ & 1 & - & - & - & - \\
\hline $6^{\prime \prime \prime}$-Feruloylspinosin & 0.029 & 0.185 & $0.826^{* *}$ & 0.389 & $0.711^{*}$ & $0.649^{*}$ & $0.622 *$ & 1 & - & - & - \\
\hline Salvianolic acid B & -0.169 & 0.035 & $0.771^{* *}$ & 0.480 & $0.847^{* *}$ & $0.650^{*}$ & $0.619^{*}$ & $0.947^{* *}$ & 1 & - & - \\
\hline Schisandrin & -0.295 & 0.106 & $0.605^{*}$ & 0.236 & 0.530 & $0.602 *$ & 0.600 & 0.492 & 0.575 & 1 & - \\
\hline Deoxyschisandrin & -0.291 & 0.130 & 0.315 & 0.321 & -0.016 & 0.591 & $0.634 *$ & -0.159 & -0.082 & 0.361 & 1 \\
\hline
\end{tabular}

Mean \pm S.D., $n=6$.

vious methods, this UHPLC-TSQ-MS/MS method obtained lower LLOQ results. Additionally, the UHPLC-TSQ-MS/MS analysis time for the 11 components was shorter than a previous HPLC-MS/MS ${ }^{34)}$ method that simultaneously quantified 7 active ZAP components in an earlier stage of this study. This indicates that the method adopted in this study can simultaneously determine multiple components with high sensitivity and a short analysis time.

Method Validation To optimize the ESI conditions for the 7 ZAP components and 4 monoamine neurotransmitters plus IS, we investigated both positive and negative ionization modes. Danshensu, protocatechualdehyde, spinosin, 6"'-feruloylspinosin, salvianolic acid B and IS had stronger signal responses and less background noise under negative ion mode, whereas schisandrin, deoxyschisandrin, NA, DA, 5-HT and 5-HIAA had higher signal responses under positive ion mode. Multiple reaction monitoring was performed and the fragment pathways are shown in Table 1. The representative MRM-extracted ion chromatograms of blank plasma samples, blank plasma spiked with the eleven analytes at LLOQ and IS $(1.00 \mathrm{ng} / \mathrm{mL})$, and samples obtained at $0.5 \mathrm{~h}$ after intragastric dosing of ZAP are shown in Fig. 2. The results indicated that the analytical conditions could be successfully applied for the simultaneous determination of the 7 ZAP constituents and 4 monoamine neurotransmitters.

The standard curves, linear range, correlation coefficient and LLOQ of all components in plasma are presented in Table 2. The correlation coefficients $(r)$ were greater than 0.9942 , which indicated each component had good linearity. The RSD values of all 11 components were all less than $14.92 \%$ in plasma at three concentration levels. The RE values of the 11 components in plasma samples were within $\pm 14.92 \%$ (Table 3). The results showed that the established UHPLCTSQ-MS/MS method was reliable and reproducible for the determination of the 11 components in rat plasma. The extraction recovery and matrix effect of the 11 components and IS at three concentration levels in plasma are presented in Table 3. The recovery rate of the 11 target components ranged from 73.94-101.06\%. The matrix effect for the 11 target components ranged from $80.06-105.70 \%$. These results indicated that the method had no co-eluted substances that affected separation and ionization. The stability of all components in plasma was detected at four different storage conditions (Table 4). The result showed that there was no obvious degradation of any of the components under different storage environments, which indicated that all the components in plasma were stable during the treatment process. Thus, the validated UHPLCTSQ-MS/MS method was suitable for large-scale detection.

Pharmacokinetics Study The developed and validated UHPLC-TSQ-MS/MS method was applied to determine the 7 ZAP constituents in rat plasma after intragastric administration of ZAP $(15 \mathrm{~g} / \mathrm{kg})$. The mean plasma concentration-time curve profiles are shown in Fig. 3. The pharmacokinetic parameters for each component are presented in Table 5. It has been reported that multiple dosing changed the pharmacokinetic parameters compared to single dosing, ${ }^{39,40)}$ which was in accordance with the obtained pharmacokinetic parameter results in this study and our previously estimated values. ${ }^{34)}$ Danshensu, protocatechualdehyde, salvianolic acid B and 6 "'-feruloylspinosin were rapidly eliminated with $T_{1 / 2}$ values less than $4 \mathrm{~h}$, whereas spinosin, schisandrin, and deoxyschisandrin had slower elimination with $T_{1 / 2}$ values from 4-7 h. Danshensu, protocatechualdehyde, salvianolic acid B, 6"'-feruloylspinosin, schisandrin and deoxyschisandrin were rapidly absorbed with a $T_{\max }$ lower than $0.5 \mathrm{~h}$, whereas spinosin was relatively slowly absorbed with a $T_{\max }$ of approximately $5 \mathrm{~h}$. The lower absorption of spinosin may be due to the increased expression of efflux transporters (P-gp, MRP, and BCRP) in the middle and upper part of the intestinal tract compared with the lower part of the intestinal tract. ${ }^{41,42)} \mathrm{Ad}-$ ditionally, schisandrin and deoxyschisandrin exhibited doublepeak phenomena. This behavior was similar to the results of a previous investigation ${ }^{29,36)}$ and might be due to hepatoenteric circulation. The pharmacological activities of the above components were all observed in the rats.

Correlation Analysis As shown in Table 6, 5-HT was significantly positively correlated with spinosin, danshensu, 6 "'-feruloylspinosin and salvianolic acid B $(p<0.01)$. According to the literature, spinosin may exert sedative-hypnotic effects by activating $5-\mathrm{HT}_{1 \mathrm{~A}}$ and $\gamma$-aminobutyrate (GABA) receptors, ${ }^{19,20,43)}$ while salvianolic acid $\mathrm{B}$ protects cognitive function through the regulation of 5-HT to inflammatory mediators. ${ }^{44,45)}$ The sedative effects of $6^{\prime \prime \prime}$-feruloylspinosin may occur by enhancing the expression of the GABA receptor. ${ }^{33)}$ Danshensu can increase 5-HT, NA and DA levels by inhibiting monoamine oxidase. ${ }^{24)}$ Moreover, studying the correlation of endogenous and exogenous components can explain their possible mechanisms during disease. ${ }^{46}$ ) This suggested that the anti-insomnia mechanism of ZAP may be due to its main components increasing 5-HT levels. 
Moreover, there was a significant and positive correlation between DA and NA; spinosin and danshensu; and salvianolic acid B, 6"'-feruloylspinosin and protocatechualdehyde. NA and DA have synergistic effects on prefrontal cortex-related nervous activity function. ${ }^{47)}$ The other five components with positive correlations, including spinosin, danshensu, salvianolic acid B, 6"'-feruloylspinosin and protocatechualdehyde, demonstrated the synergistic effects of Danshen (the minister drug) and Suanzaoren (the sovereign drug) in ZAP on anti-insomnia from a chemical point of view.

\section{Conclusion}

In the current study, we developed a UHPLC-TSQ-MS/MS method for the simultaneous determination of 7 ZAP constituents and 4 endogenic components in rat plasma. The results suggested that danshensu, spinosin, 6"'-feruloylspinosin and salvianolic acid B might promote 5-HT levels in the body, leading to anti-insomnia effects.

Acknowledgments This study was supported by the Key Research and Development Plan in Shaanxi province (2018ZDXM-SF-014), Shaanxi Provincial Education Department Serves Local Special Projects (2018JC032); and the open funding of Key Laboratory of Resource Biology and Biotechnology in Western China, Ministry of Education, Northwest University (ZSK2018006). Public health specialty in the Department of Traditional Chinese Medicine (Grants No. 2018-43).

Conflict of Interest The authors declare no conflict of interest.

\section{References}

1) Li C., Jia F. J., Du H. R., Sun Y. X., Li Z. W., Fang Z. F., hin. Psychiatr., 32, 33-35 (1999).

2) Chen K. C., Sun M. F., Yang S. C., Chang S. S., Chen H. Y., Tsai F. J., Chen C. Y., Chem. Biol. Drug Des., 78, 679-688 (2011).

3) Comella C. L., J. Neural. Transm. Suppl., 349-355 (2006).

4) Carr G. V., Lucki I., Psychopharmacology, 213, 265-287 (2011).

5) Andrew R., Watson D. G., Best S. A., Midgley J. M., Wenlong H., Petty R. K., Neurochemical, 18, 1175-1177 (1993).

6) McEwen B. S., Brinton R. E., Chao H. M., Coirini H., Gannon M. N., Gould E., Callaghan O. J., Spencer R. L., Sakai R. R., Woolley C. S., The hippocampus: a site for modulatory interactions between steroid hormones, neurotransmitters and neuropeptides, "Neuroendocrine Perspectives," ed. by Müller E.E., MacLeod R.L., SpringerVerlag New York Inc., New York, 1990, pp. 93-133.

7) Wei B. B., Li Q., Fan R. H., Su D., Chen X. H., Jia Y., Bi K., J. Pharm. Biomed. Anal., 88, 416-422 (2014).

8) Gardner C. R., Tully W. R., Hedgecock C. J., Prog. Neurobiol., 40, $1-61(1993)$

9) Youssef N. A., Rich C. L., Ann. Clin. Psychiatry, 20, 157-169 (2008).

10) Li J., Liu Q. T., Chen Y., Liu J., Shi J. L., Liu Y., Guo J. Y., Evidence-Based Complementary Alternative Medicine, 3, 1-10 (2016).

11) Becker P. M., Somiah M., Sleep Med. Clin., 10, 57-76 (2015).

12) Saletu-Zyhlarz G. M., Abu-Bakr M. H., Anderer P., Gruber G. Mandl M., Strobl R., Gollner D., Prause W., Saletu B., Prog. Neuropsychopharmacol. Biol. Psychiatry, 26, 249-260 (2002).

13) Emens J. S., Burgess H. J., Sleep Med. Clin., 10, 435-453 (2015)

14) Peng Z. C., Zhu J. J., Lishizhen Med. Medica Res., 2001, 86-87 (2001).
15) Ahn N. Y., Jung J. W., Oh H. R., Shin J. S., Hyeon S. Y., Lee B. K., Cheong J. H., Ryu J. H., Appl. Pharmacol., 12, 151-156 (2004).

16) Han H. S., Ma J. Y., Eun S., Hong J. T., Oh K. W., Biomolecules \& Therapeutics, 15, 175-181 (2007).

17) Jiang J. G., Huang X. J., Chen J., Lin Q. S., Nat. Prod. Res., 21, $310-320(2007)$

18) Kawashima K., Saito K., Yamada A., Obara S., Ozaki T., Kano Y., Biol. Pharm. Bull., 20, 1171-1174 (1997).

19) Wang L. E., Cui X. Y., Cui S. Y., Cao J. X., Zhang J., Zhang Y. H., Zhang Q. Y., Bai Y. J., Zhao Y. Y., Phytomedicine, 17, 404-409 (2010).

20) Jung I. H., Lee H. E., Park S. J., Ahn Y. J., Kwon G., Woo H., Lee S. Y., Kim J. S., Jo Y. W., Jang D. S., Kang S. S., Ryu J. H., Pharmacol. Biochem. Behav., 120, 88-94 (2014).

21) Wu X. J., Wang Y. P., Wang W., Sun W. K., Xu Y. M., Xuan L. J., Acta Pharmacol. Sin., 21, 855-858 (2000).

22) Tang M. K., Ren D. C., Zhang J. T., Du G. H., Phytomedicine, 9, 405-409 (2002).

23) Lin Y. H., Liu A. H., Wu H. L., Westernbroek C., Song Q. L., Yu H. M., Ter Horst G. J., Li X. J., Biochem. Biophys. Res. Commun., $\mathbf{3 4 8}$ 593-599 (2006).

24) Kwon G. Y., Kim H. J., Park S. J., Lee H. E., Woo H., Ahn Y. J., Gao Q., Cheong J. H., Jang D. S., Ryu J. H., Life Sci., 101, 73-78 (2014).

25) Qu W., Huang H., Li K., Qin C., Pathol. Biol., 62, 348-353 (2014).

26) Liu H. X., Liu Y., Zhang J. W., Li W., Liu H. T., Yang L., Drug Metab. Dispos., 36, 1562-1569 (2008).

27) Chang Z. Q., Gebru E., Lee S. P., Rhee M. H., Kim J. C., Cheng H., Park S. C., Nutr. Sci. Vitamind., 57, 118-122 (2011).

28) Zhang C. N., Zhao X., Mao X., Liu A. J., Liu Z., Li X. L., Bi K. S., Jia Y., Eur. J. Pharmacol., 744, 157-163 (2014).

29) Lee H. J., Kim C. Y., Food Chem., 120, 1224-1228 (2010).

30) Liu H. T., Lai H. U., Jia X. Y., Liu J. S., Zhang Z., Qi Y. D., Zhang J., Song J. B., Wu C. M., Zhang B. G., Xiao P. G., Phytomedicine, 20, 1135-1143 (2013)

31) Sowndhararajan K., Deepa P., Kim M., Park S., Kim S., Biomed. Pharmacother., 97, 958-968 (2018).

32) Lee H. J., Kim C. Y., Food Chem., 120, 1224-1228 (2010).

33) Qiao L. D., Liu Y., Chen X., Xie J., Zhang Y., Yang K., Zhou H., Duan Y., Zheng W., Xie W., Pharmaceutical and Biomedical Analysis, 121, 77-83 (2016).

34) Zhao A. J., Zhang L., Li R., Shang J., Yi H. H., Zhang D., Wang S. X., Fang M. F., Biomed. Chromatogr., 32, 1-10 (2017).

35) Xue G. Q., Cao B. S., Gao S. L., Zhang J., Pan X. Y., China Pharmacy, 29, 1213-1217 (2018).

36) Sun H., Wu F., Zhang A., Wei W., Han Y., Wang X., J. Sep. Sci., 36, 485-491 (2013)

37) Li Y. J., Liang X. M., Xiao H. B., Bi K. S., J. Chromatogr. B Analyt. Technol. Biomed. Life Sci., 787, 421-425 (2003).

38) Li Y. J., Sui Y. J., Dai Y. H., Chromatographia, 67, 335-337 (2008).

39) Wu W. M., Wang J., Huang C. K., Wang Z. S., Wu X. G., Chinese J. Clin. Pharm., 22, 77-81 (2013).

40) Vatsavai L. K., Kilari E. K., J. Exp. Pharmacol., 8, 69-76 (2016).

41) Cascorbi I., Pharmacol. Ther., 112, 457-473 (2006).

42) Seithel A., Karlsson J., Hilgendorf C., Björquist A., Ungell A. L. Eur. J. Pharm. Sci., 28, 291-299 (2006).

43) Wang L. E., Zhang X. Q., Yin Y. Q., Zhang Y. H., J. Pharm. Pharmacol., 64, 277-282 (2012).

44) Mössner R., Daniel S., Schmitt A., Albert D., Lesch K. P., Life Sci., 68, 873-880 (2001)

45) Yang W., Wang Q., Kanes S. J., Murray J. M., Nishikura K., Brain Res. Mol. Brain Res., 124, 70-78 (2004).

46) Al-Amodi H. S., Abdelbasit N. A., Fatani S. H., Babakr A. T., Mukhtar M. M., Diabetes Metab. Syndr., 12, 357-364 (2018).

47) Xing B., Li Y. C., Gao W. J., Brain Res., 1641 (Pt B), 217-233 (2016). 